\title{
Proceedings of the Joint Meeting of the Society of British Neurological Surgeons (112th Meeting), the Neurosurgical Society of Australia and the Neuroanaesthetists Travelling Club - Oxford, 14-15 April, 1988
}

PREDICTION OF RECURRENCE IN MENINGIOMAS USING DNA ANALYSIS

PL May, J Broome, J Lawry, RDE Battersby, Departments of Neurosurgery and Neuropathology, Sheffield

Despite the complete macroscopic removal of meningiomas there is a significant rate of recurrence approaching $20 \%$ at 20 years in some recent series. The prediction of recurrence by clinical or histopathological means is inadequate. Flow cytometric analysis of DNA in meningiomas has shown a correlation between aneuploidy, a high proliferative index $(\% \mathrm{~S}+\% \mathrm{G} 2 / \mathrm{M})$ and clinically aggressive behaviour. ${ }^{1}$ Accordingly the DNA analysis of meningiomas may be of value in predicting recurrence of these tumours. To test this hypothesis we compared the cellular DNA of archival embedded tissue from known recurrent meningiomas with a group of non recurrent tumours. Both groups had comparable periods of follow up.

Forty patients with total macroscopic removal at the time of surgery were analysed. The paraffin blocks of their tumours were classified histologically (according to the WHO) and sections taken for flow cytometry. DNA analysis showed that the proliferative index of the recurrent group (range: 10-30\%) was higher than that of the non recurrent group (range: 5-20\%; p < 0.002 Mann-Whitney).

Although these numbers are small our results suggest that flow cytometry may be of value in the prediction of recurrence of histologically benign, macroscopically removed meningiomas. A proliferative index of greater than $20 \%$, in the presence of total macroscopic removal and benign histological appearance, strongly suggests that late tumour recurrence may occur. A prospective study is at present being undertaken to verify this hypothesis.

\section{Reference}

1 Ironside JW, Battersby RDE, Lawry J, et al. J Neurosurg 1987;66:588-94.
WILL CHROMOSOME KARYOTYPING OF MENINGIOMAS AID PREDICTION OF TUMOUR RECURRENCE? A PROSPECTIVE STUDY

R Strachan, C Clarke, M Nurbhai, S Marks, Departments of Neurosurgery, Cytogenetics and Neuropathology, Middlesborough

Cytogenetic studies over many years have established an absence or partial deletion of chromosome 22 as a common finding in meningiomas. Enormous karyotypic variation is recognised: an abnormal hyperdiploid clone can occur in an histologically benign meningioma. We considered that cytogenetic studies might help to predict more accurately those tumours that recur and examined prospectively the cytogenetic, histopathological and macroscopic findings in 13 meningiomas. Where the neuropathologist reported the presence of malignant change, a cytogenetically abnormal clone was more common in short term culture of the tumour tissue. However, histologically benign meningiomas showed great cytogenetic variation, from normal chromosomes to hyperdiploid clones with extensive karyotypic abnormality indicating malignant change. We suggest that both cytogenetic findings and histopathological features are used to assess "malignancy" in meningiomas and the risk of recurrence or regrowth.

MOBILISATION OF THE ZYGOMATIC BONE IN SURGERY FOR LESIONS OF THE MIDDLE CRANIAL FOSSA AND PETROUS APEX. A SERIES OF 26 PATIENTS

HT Marsh, D Archer, D Uttley, BA Bell, Atkinson Morley's Hospital, London

Surgical access to the medial part of the middle cranial fossa is restricted by the anatomy of the skull base and in particular by the zygomatic bone and temporalis muscle. Access to the inner sphenoid wing, cavernous sinus and petrous apex can be greatly improved, and the degree of brain retraction required greatly reduced, if the zygomatic bone is mobilised laterally and downwards, so that the temporalis muscle can be reflected below the level of the floor of the middle fossa. ${ }^{\prime}$

We have used a more radical version of this approach in 26 patients (June 1986 to March 1988): 16 meningiomas, 2 pituitary adenomas, 1 metastasis, 1 chondrosarcoma, 5 basilar aneurysms and 1 AVM. The cosmetic result has been highly satisfactory with only four patients developing a fairly modest degree of temporalis muscle atrophy and only one patient with a permanent frontalis nerve palsy. The screw holding the zygomatic bone in place came adrift in one patient but surgical reduction was not required.

The mobilisation of the zygomatic bone adds approximately 30 minutes to the overalb time of the procedure and has minima席 morbidity. We cannot prove that this tech $\frac{\mathrm{P}}{\mathrm{D}}$ 음 nique improves surgical results but considen $\rightarrow$ that it has enabled more radical surgery to be carried out on some of these lesions.

\section{Reference}

1 Fujitsu K, Kuwabara T. J Neurosurg 1985;62 340-3.

LE FORT I OSTEOTOMY; A NEW APPROACH TO TUMOURS IN AND AROUND THE CLIVUS

A Moore, DJ Archer, D Uttley, Atkinson Morley's Hospital and Royal Marsden Hospital, London

Over the past fifty years, the transoral surgical approach to the clivus and upper cervical spine has been used in the treatment of a variety of lesions, including the excision of intra- and extradural tumour, clipping of vertebro-basilar aneurysms and correction of congenital craniospinal abnormalities. However, the outcome of surgery has frequently been complicated by difficulties of access to the upper clivus and pharyngeal wound breakdown with subsequent development of CSF fistula and meningitis. A new approach to this problem utilises a Le Fort I osteotomy to improve exposure of the clivus in the approach to vertebro-basilar aneurysms ${ }^{\prime}$ thus facilitating control of the aneurysm and reducing the risk of post- 
traumatic CSF fistula. The same approach, via maxillotomy, has enabled partial or total tumour resection in 11 consecutive procedures on 9 patients presenting with tumours of the skull base, or at the craniocervical junction. Neurological status was either improved or unchanged in all patients post-operatively, and pain relief was obtained in $71 \%$ of cases where this was a presenting symptom. No patient developed a CSF fistula following surgery. Methods of closure and the use of puncture pharyngostomy were discussed. Cosmetic results were good, and no problems related to malocclusion were reported. This approach may be used to advantage in the surgical treatment of skull base tumours.

\section{Reference}

1 Archer DJ, Young S, Uttley D. J Neurosurg 1987;67:54-8.

\section{COMBINED CRANIOFACIAL APPROACH TO THE} TREATMENT OF SKULL BASE TUMOURS M Poole, M Briggs, Oxford

Our experience of exposure and reconstruction, gained in the treatment of congenital craniofacial abnormalities, has emphasised the importance of a team approach, involving plastic surgeons and neurosurgeons. We have applied the same strategy to the management of acquired conditions such as craniofacial trauma and base of skull tumours. Thirty six patients with base of skull tumours have been treated (14 malignant, 8 benign, 14 dysplasia). Complications have included intracranial haematoma (2), temporary diabetes insipidus (2), epilepsy (2), infection (1), aerocoele (1) and deep vein thrombosis with pulmonary embolism (1). All patients with benign pathology remain alive and well.

\section{EFFECT OF ORAL NIMODIPINE ON THE} INCIDENCE OF CEREBRAL INFARCTION AND OUTCOME AT THREE MONTHS FOLLOWING SUBARACHNOID HAEMORRHAGE: THE BRITISH ANEURYSM NIMODIPINE TRIAL (B.R.A.N.T.) JD Pickard, GD Murray, R Illingworth, MDM Shaw, GM Teasdale, PM Foy, PRD Humphrey, DM Lang, RJ Nelson, $P$ Richards, J Sinar, S Bailey, A Skene, Southampton, London, Liverpool, Glasgow

Patients with subarachnoid haemorrhage (n $=554$ ) proven by lumbar puncture or CT scan or both, were admitted within 96 hours of the ictus to a double blind placebo controlled trial and randomly allocated either to placebo or to oral nimodipine $60 \mathrm{mg}$ four hourly for 21 days. The end points specifically looked at prospectively were firstly, the occurrence of cerebral infarction and/or ischaemic deficit and secondly, the overall neurological/functional outcome at three months after entry. The size of the trial was chosen so that it had an $80 \%$ chance with an alpha of 0.05 of detecting a $50 \%$ reduction in the incidence of cerebral infarction, presuming the incidence to be at least $15 \%$.

The trial closed in September 1987. Oral nimodipine reduced the incidence of cerebral infarction by $34 \%(p<0.01)$ and reduced bad outcomes (death, vegetative and severe disability) by $40 \%$ (p $<0.001)$.

\section{SUCCESSFUL CRANIOTOMY FOR AN}

INTRACRANIAL ABSCESS IN 1667

GT Martin, Wellington, New Zealand

Pre-Listerian cranial surgery was very different from the present as the scalp was not closed primarily, but allowed to granulate. Both compound fractures and osteomyelitis of the skull were recognised and trephination used to try and prevent or treat extradural abscesses.

HRH Prince Rupert sustained a minor pistol wound of the scalp at the age of 27 followed, 17 years later, by headache and sickness after a pulley block fell on his head. When 47 years old, the illness recurred and was relieved by trephination and drainage. The surgical technique has been reconstructed from the papers of his surgeon's apprentice, Pepys diary and contemporary texts. On the first day, the scalp was shaved followed, in the sitting position, by a circular incision and detachment of the periosteum, packing and dressing of the wound. He was then cupped, scarified, bled and clystered. The next day, trephination was performed, left open to drain and dressed without a drainage tube. A fortnight later, Prince Rupert was well enough to make, in his own workshop, some forceps to better dress his wound. He died aged 62 of a chest infection, confirmed by necropsy.

OBSERVATIONS ON THE PATHOPHYSIOLOGY OF CHRONIC SUBDURAL HAEMATOMA IN THE

ELDERLY: SIR HUGH CAIRNS MEMORIAL ESSAY PRIZE 1988

RJ Nelson, Southampton

In a series of prospective and retrospective studies the neurological deficit, depression of conscious level and severity of hemiparesis, observed in elderly patients with chronic subdural haematomas (CSDH) was correlated with their computerised tomographic (CT) scan findings, changes in cerebral blood and Neuroanaesthetists Travelling Clu矢

flow (CBF), and subdural pressures.

Ten patients (seven men, three womend mean age 73 , range $59-85$ years) were studie before and after burr hole drainage of CSDH under local anaesthesia. Mean hemi sphere CBF ipsilateral to the CSDH, 45 (SD 12) $\mathrm{ml} / 100 \mathrm{~g} / \mathrm{min}$ (measured by the modified intravenous ${ }^{133}$ Xenon technique ${ }^{1}$ ) was nol significantly different from mean contra lateral hemisphere CBF, 46, (SD 15) $\mathrm{ml} / 10 \notin$ $\mathrm{g} / \mathrm{min}$. There was no correlation between pré: or post operative $\mathrm{CBF}$, and neurologica $\bar{b}$ deficit or pattern of clinical recovery. All 18 patients made a good recovery. Subduraf pressures ranged from 4 to $16 \mathrm{~mm} \mathrm{Hg}$ anc. were not obviously related to the extent of neurological deficits.

Impairment of conscious level or the्छ development of a hemiparesis was associated on the CT scan with shift of the midline structures (septum pellucidum at the level of the caudate nuclei) exceeding 7\% which was partly the result of swelling of subcorticat structures of the ipsilateral hemisphere (low attenuation in the white matter), a pathoir logical observation made in $1951 .^{2}$ A close correlation was observed between the extont of ipsilateral hemisphere swelling and thew severity of neurological deficit, particula motor weakness, in both the prospective a retrospective study (63 patients). $\varrho-$

In a second retrospective study the car ₹iक arteriograms and venograms of $23 \mathrm{CSBH}$ patients whose diagnoses were establistuect angiographically before the advent of scanning $\cdot(1965-74)$ were examined foro evidence of spasm or occlusion in the arteria supply or venous drainage of the deep struc: tures of the hemispheres. Filling of the choroidal and perforating arteries was present in all patients even in the presence o $\bar{b}$ gross anterior cerebral artery displacement Effacement of the basal vein of Rosentha and/or the internal cerebral vein occurred more commonly in patients with a severe hemiparesis, whatever the degree of subfal cine herniation.

The author concluded that gross changes. in hemisphere CBF were not the primary determinant of neurological disability in CSDH patients. A hypothesis was proposed in which a CSDH, acting as a low pressure mass lesion, induces subfalcine herniation which, when critical, results in impairment of venous or extracellular fluid drainage from the central part of the hemisphere. It was further proposed that fluctuations in cons $\rightarrow$ cious level, improvements in neurologica? deficits associated with dexamethasone therapy and postoperative deteriorations, often attributed to low-pressure states in CSDH patients, might be related to changes 


\section{Neuroanaesthetists Travelling Club}

in hemisphere swelling.

\section{References}

1 Pickard JD, Read DH, Lovick AHJ. In: Hartmann A, Hoyer S, eds. Cerebral Blood Flow and Metabolism Measurements. New York: Springer Verlag, 1985:149-52.

2 Browder J, Rabiner AM. Ann Surg 1952;131: 369-77.

REVIEW OF ONE HUNDRED CASES OF POSTERIOR CERVICAL WIRING AND FUSION FOR CERVICAL SPINE INSTABILITY K Langford, W Dunham, University of Birmingham, Alabama and Australia

We have become convinced that the maintenance of good anatomical alignment and permanent stabilisation of potentially unstable cervical spines as a result of trauma is best managed in many cases by a very simple wiring technique that does not necessitate the use of more than one $\mathbf{1 8}$ gauge wire per level and does not require sub-laminar dissection. The wire was looped through a transverse hole in the superior part of the base of the upper spinous process and under the lower spinous process. Bone grafts were placed laterally. The patients were mobilised early in a Philadelphia collar and discharged home or to rehabilitation within a few days. A review of 100 cases treated between 1980 and 1987 has demonstrated the safety and efficiency of the technique with no recorded loss of neurological function and the successful stabilisation in all cases done by the technique with only minimal complications. We feel that the more complicated techniques reported may not be necessary and introduce more potential complications.

\section{TRIGEMINAL NEUROMAS: A REVIEW OF 11} CASES

\section{Bordi, L Symon, London}

This rare lesion was first described in $\mathbf{1 8 3 6}$ and may masquerade as an acoustic schwannoma or apex meningioma with the true diagnosis being made at operation. Eleven cases have presented to us since 1968: four male and seven female patients with an age range of 17-70 years (mean age of 40) at diagnosis. One patient had neurofibromatosis with subcutaneous nodules, bilateral acoustic neuromas, a glossopharyngeal neuroma and a small tentorial meningioma.

Symptoms at presentation were generally those of cerebellopontine angle and petrous apex space-occupying lesions with diplopia, nystagmus, unsteadiness, reduction of hearing, depressed corneal reflex, reduction of light touch and pin-prick sensation over one or all of the divisions of the trigeminal nerve, wasting of the masseter, and jaw deviation on mouth opening.

We use a retromastoid incision and posterior fossa craniectomy for lesions restricted to the cerebellopontine angle, but use a combined supra/infratentorial approach if there is a significant middle fossa component. All tumours were larger than $3 \mathrm{~cm}$ in diameter and total excision was sometimes not possible (seven patients) owing to the involvement of the cavernous carotid artery or the inferior orbital fissure.

There was no peri- or post-operative mortality, and over a mean follow up period of 4.5 years the outcome has been good for 10 of the 11 patients, and even with subtotal removal there are no signs of clinical recurrence.

\section{RECENT EXPERIENCE WITH DOPAMINE}

TRANSPLANTATION FOR PARKINSON'S DISEASE ER Hitchcock, Midland Centre for Neurosurgery and Neurology, Birmingham

Recent developments in cellular transplantation has given encouraging evidence of the feasibility of neural tissue transplantation for the relief of several serious degenerative nervous disorders. To date only Parkinsonism has been so treated by the transplantation of either autologous adrenal medulla or foetal substantia nigra into the brain of patients suffering from Parkinsonism.

The problems of this type of transplantation were discussed including the surgical technique, the difficulties of tissue recognition and the ethical background. The author presented his initial results in three patients, one using adrenal medulla and two with foetal anterior midbrain. The early effects, when taken in the context of those being reported worldwide, support the need for further, systematic study.

\section{THE REJECTION OF NEURAL TISSUE} ALLOGRAFTS WITHIN THE CENTRAL NERVOUS SYSTEM

RSC Kerr, PF Bartlett, AH Kaye, Radcliffe Infirmary, Oxford, The Walter and Eliza Hall Institute of Medical Research, and the Higginbotham Neuroscience Laboratory, Royal Melbourne Hospital, Melbourne, Australia

The central nervous system is classically considered to be a site of immune privilege. A lack of MHC antigen expression, the blood brain barrier and an absence of defined lymphatic pathways are thought to account for this. Consequently, in the rapidly advancing field of neural tissue transplantation, little attention has been paid to the question of graft rejection. However, it is now apparent that neural tissue grafts in certain sites are rejected, but the important question of the response to such grafts placed directly into the host neuropil remains unanswered.

To investigate this, an immunologically precisely defined mouse model has been set up using the neuronal cell surface marker Thy-1 to identify specifically the grafted tissue.

The syngeneic (Thy-1 congeneic) grafts were found to grow enormously, did not express either Class I or Class II MHC antigens and after 12 weeks showed no evidence of rejection. In contrast, allografts induced a large mononuclear cell infiltrate, expressed both Class I and later Class II MHC antigens and were fully rejected within 12 weeks. Furthermore, the blood brain barrier was not reconstituted within the allografts; these results indicate that the CNS can no longer be considered a site of immune privilege.

Utilising grafts of specific sub-populations of neuroepithelial cells, it may be possible to overcome this rejection response without resorting to the use of immunosuppressive agents.

POST-TRAUMATIC VASOSPASM: A

TRANSCRANIAL DOPPLER ULTRASOUND STUD AND PILOT TRIAL OF THE CALCIUM

ANTAGONIST NICARDIPINE

JS Compton, T Lee, PJ Teddy, Oxford

Vasospasm has been long known to occur following severe head injury but the lack of an easily-performed non-invasive reliable method for its detection has prevented detailed study of its incidence and natural history. Transcranial Doppler ultrasound (TCD), may fulfil these requirements. Our definition of vasospasm was derived from study of patients with subarachnoid haemorrhage where $80 \%$ have angiographically demonstrable arterial narrowing if the middle cerebral artery Doppler flow velocity (DFV) rises above $100 \mathrm{~cm} / \mathrm{sec}$ Twenty five patients with head injury (mean age 29 range $11-70 ; 18$ males, 7 females; average Glasgow Coma Score 5) were managed conventionally and monitored 12 hourly by transcranial Doppler. Twenty patients survived more than 24 hours. In 17 patients, DFV started to exceed $100 \mathrm{~cm} / \mathrm{s}$ between 12 hours and 4 days and remained high for 12 hours to 14 days. These preliminary data confirm that vasospasm as defined by TCD is common following severe head injury but correlation with clinical progress 
will require parallel studies of internal carotid artery velocity, intracranial pressure, arterial blood pressure and blood gases.

We also wished to determine if the increase in DFV could be reversed by a calcium channel blocker (Nicardipine-Syntex). In a preliminary open study of 37 patients $(25$ male, 12 female; mean age 29 range $11-70$; average Glasgow Coma score 5), DFV rose above $100 \mathrm{~cm} / \mathrm{s}$ for 6 hours in 48 hemispheres. Nicardipine was infused at up to 5 $\mathrm{mg} /$ hour for 24 hours in 10 patients: after 12 hours of treatment, DFV fell and after cessation of the drug, DFV rose but remained lower than in the untreated group. The infusion was well tolerated. We suggest that these results justify a double-blind, placebo controlled trial that will relate changes in DFV to outcome and systemic parameters.

\section{STEREOTAXIC-CT INTEGRATED INTERSTITIAL BRACHYTHERAPY FOR MALIGNANT BRAIN TUMOURS}

F Afshar, P Hamlyn, N Plowman, E Thompson, Departments of Neurosurgery, Radiotherapy and Medical Physics, St Bartholomew's Hospital, London

Radiation therapy has remained the most effective modality for treating malignant brain tumours following surgical excision or biopsy. However, the dose of irradiation that can be delivered by external beam without causing severe brain damage is insufficient to halt or delay growth of these tumours. Since primary malignant brain tumours are a localised disease, interstitial radiotherapy using a stereotaxic-CT integrated technique for the placement of a single or multiple catheters for brachytherapy is a therapeutic technique which merits study.

The authors described the background theory, the physical properties of the various sources used; gold 198, iridium 192 and caesium 137, the source-design, and consequent dosimetries achieved. Nine patients were treated for recurrent high grade gliomas, two for low grade gliomas and one for PNET (neuroblastoma) tumour. Eight patients were treated using the Bennett stereotactic frame with the EMI head scanner and General Electric 9000CT scanner. The remainder had been treated using the Brown-Robert-Wells stereotactic apparatus and the General Electric 9800 scanner. The advantages of each system were described together with the specifically designed NIH arc system which enables the use of guide blocks with a large area in order to approach a large target area with a single arc setting and was ideal for the placement of a broad array of multiple parallel catheters. Delineation of tumour margins using tissue impedence measurements was described. The preliminary results of 13 cases were shown of both adults and children together with details of obtaining optimal trajectory angles and the rationale for the placement of multiple sources.

\section{CT COMPUTERISED STEREOTACTIC BIOPSY FOR} LOW DENSITY CT LESIONS PRESENTING WITH EPILEPSY

JN Wilden, PJ Kelly, Institute of Neurological Sciences, Glasgow, and Mayo Clinic, Rochester, USA

The diagnostic dilemma presented by patients presenting with epilepsy alone and non-enhancing low-density lesion on CT scan was explored using computer-assisted CT-guided stereotactic biopsy ${ }^{1}$ with stereotactic angiographic control (for the drill biopsy technique). The tissue diagnosis ${ }^{2}$ in 35 patients (mean age 41.8 years) was astrocytoma (Grade 1:2; Grade 2:13; Grade 3:2; Grade 4:1), oligodendroglioma (Grade 2:6; Grade 3:1), mixed oligo-astrocytoma (Grade 2:5; Grade 3:2), ganglioglioma 2 and one patient remained undiagnosed.

Three patients underwent a computerassisted stereotactic laser resection and 28 patients had radiotherapy. Stereotactic biopsy in these patients was uncomplicated and facilitated both provision of a prognosis and subsequent management.

\section{References}

1 Wilden JN, Kelly PJ. J Neurol Neurosurg Psychiatry 1987;50:1302-5.

2 Daumas-Duport C, Monsaingeon VN, Guyen JP, Missir O, Szikla G. Acta Neurochir, Suppl 1984;33:171-81.

THE RESULTS OF STEREOTACTIC

RADIOSURGERY IN ARTERIOVENOUS

MALFORMATIONS AT ONE YEAR

PS Dias, AA Kemeny, DMC Forster, Sheffield

The stereotactic radiosurgical treatment of intracranial arteriovenous malformations in the Department of Neurosurgery in Sheffield started in September 1985. The authors provided a comprehensive audit of the patients, the types and size distribution of the malformations as well as the method of selection and treatment.

Hitherto, 52 patients (mean age 30 years, range 8-60) were available for follow-up angiography one year after treatment. Twenty six $(50 \%)$ had complete or almost and Neuroanaesthetists Travelling Clu\$

complete obliteration of the malformatio and a further $17(33 \%)$ showed significanf reduction in size. Greater success was achieved, at least at 1 year, with laterall placed lesions and younger patients. Thefe was no morbidity, apart from slight nause-̧ and vomiting lasting less than 24 hours wiț some posterior fossa lesions.

Previous studies with the same method in Stockholm have indicated that the prospects. of a larger proportion of cases showin $\overrightarrow{5}$ complete radio-obliteration after two years+ is very good.

THORACIC INTER VERTEBRAL DISC PROTRUSION; EXPERIENCE OF 67 CASES

T Russell, Bristol and Edinburgh

Herniation of a thoracic intervertebral disc is relatively uncommon (1-2/million/yr). In the 67 cases treated in Bristol, myelography an $\mathbb{R}^{2}$ now magnetic resonance imaging ha proven to be the investigation of choicen There was no surgical mortality. The trans thoracic extrapleural approach had been. used in $\mathbf{4 0}$ cases $(\mathbf{8 8 \%}$ improved or returned. to normal), costotransversectomy in 12 coses (75\% improved/normal) and laminectom in 15 cases ( $47 \%$ improved; $20 \%$ worge). Early diagnosis and prompt surgical treat ment remain imperative because of the progressive and serious neurological defoci which results from delay.

PERCUTANEOUS ASPIRATION OF HERNIATED LUMBAR DISCS

JC Maroon, G Onik, JE Wilbergerọ Pittsburgh, Pennsylvania, USA

In $1985,^{12}$, Onik described a new automate lumbar disc aspiration technique that utilise 8 a probe with the guillotine cutting tech nology used in vitrectomy and arthroscopie instrumentation. The probe's small size $(2$ $\mathrm{mm}$ in diameter) minimises the risk of nerv injury, while its automated action permits. rapid, safe removal of disc material.

A multi-institutional study of 269 patient? with clinical and radiographic confirmationo of sub-posterior longitudinal ligament dis herniations was done. The average time of conservative treatment was 9 months. The procedure was performed under local anaesthesia. An 18 gauge stylet is inserted into the disc space using fluoroscopic guidance. A $2 \cdot 8$ $\mathrm{cm}$ cannula is placed over the stylet anc inserted against the annulus fibrosis. Au tubular cutting instrument is then passed through the cannula, and a hole is made with a circular cutting knife in the lateral annulusN The aspiration probe (nucleotome) with $a_{0}^{\omega}$

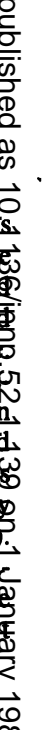

.


single side port near the distal end and containing a reciprocating surgical blade, is inserted into the disc space. The correct position is confirmed by AP and lateral fluoroscopic images. With suction aspiration and concurrent cutting, disc material is removed. Instrumentation has been devised and now used in approximately 50 cases at the L5-S1 interspace.

From 1 to $7 \mathrm{~g}$ of disc material were removed. Ninety five per cent of patients were discharged the same day. Seventy three per cent had good to excellent results with a minimum follow up period of two months. In the $27 \%$ failure group, 19 had subsequent surgery, 12 patients had free fragments of disc that had perforated the posterior longitudinal ligament. No herniation was found in three. In four, a "bulging" disc was found and in the remainder, no surgical data were available. No complications occurred except for minor short term pain at the site of needle insertion and one case of discitis. Further investigation and long term follow up are needed before definitive statements can be made, but this technique appears promising in the treatment of subposterior longitudinal ligament disc herniations.

\section{References}

1 Onik G, Helms CA, Ginsberg L, et al. Am J Neuroradiol 1985;6:290-3.

2 Maroon JC, Onik G. J Neurosurg 1987;66: 143-6.

THE RESULTS OF REMOVAL OF TEMPORAL LOBE NEOCORTEX IN THE TREATMENT OF EPILEPSY IN 40 PATIENTS

G Kaar, J Phillips, H Staunton, M Farrell, B O'Moore, Dublin

We have performed temporal lobectomy in more than 60 patients with intractable epilepsy. Forty patients have been reviewed. The follow-up period ranged from 18 months to 9 years. The patients suffered from a variety of simple partial, complex partial and secondary generalised seizures. At surgery the neocortex only was removed leaving the amygdala and hippocampus intact.

Using a slightly modified Crandall therapeutic group classification, $55 \%$ of patients became seizure free. A further $25 \%$ showed worthwhile improvement. The remainder were not significantly improved. In addition to the clinical evaluation, laterali- sation and localisation was determined by the interictal spike recording, ${ }^{1}$ in many cases elicited for the first time by intravenous methohexitone. In all cases except one, a spike was detected with surface recordings during surgery, sometimes elicited by methohexitone. ${ }^{2}$ Intraoperative depth recording from the amygdala and hippocampus was performed but these structures were left intact.

Pathological study revealed Chaslins gliosis, neuronal ectopia and other cytoarchitectural changes. Postoperative complications included permanent hemianopia and transient dysphasia or hemiparesis.

The rationale presented for the limited tissue removal was that temporal neocortex was required in many instances for the conversion of a deeper spike into a seizure. A sceptical and spirited discussion ensued.

\section{References}

1 Carey P, O'Moore B, et al. Ir Med J 1985; 78:74-7.

2 Hardiman O, Coughlan A, et al. Epilepsia 1987; 28:335-9.

INTRATHECAL BACLOFEN FOR INTRACTABLE SPASTICITY: A COMPARISON OF THE MEDTRONICS PROGRAMMABLE AND CORDIS SECOR MECHANICAL DRUG DELIVERY SYSTEMS P Teddy, B Gardner, A Jamous, National Spinal Injuries Centre, Stoke Mandeville Hospital

Intrathecal baclofen has been demonstrated to relieve intractable spasticity in spinal cord damaged patients. Several drug pump delivery systems are available. This current study compared the relative merits of the Medtronics programmable and Cordis Secor mechanical pumps.

Ten spinal cord injured patients with intractable disabling spasticity unrelieved by oral baclofen were selected following their response to a single dose of intrathecal baclofen. Myelograthy had previously demonstrated free flow to the passage of dye. The programmable pump was inserted into five of these and the mechanical pump in the others. Regular assessments were made of spasticity, functional benefit and complications and follow up extended to 2 years.

Intrathecal baclofen can be effectively delivered by both pumps. The programmable pump is more useful when precise control of dosage is critical to avoid sideeffects or to achieve optimum function. Patients not requiring such close control may be effectively managed using the mechanical pump.

\section{SPONTANEOUS SUBARACHNOID}

HAEMORRHAGE: A COMPARISON OF 199

CONSECUTIVE CASES IN THE UNITED KINGDOM AND 206 CONSECUTIVE CASES IN AUSTRALIA

G Duffy, Hobart, Australia

The author compared 199 consecutive cases of subarachnoid haemorrhage admitted under his care to a neurosurgical unit in the United Kingdom over a four year period with 206 consecutive cases in a community of half a million in Tasmania over a four year period fourteen years later.

The author emphasised the limited value of a hospital based study in determining the overall effect of treatment of subarachnoid haemorrhage unlike the information obtained from a community based study where the results of treatment can be analysed to determine the effect of that treatment on outcome from subarachnoid haemorrhage in the total community, not just those admitted largely by chance to a neurosurgical unit. Detailed review revealed the effects of introduction of CT scanning and improvement in overall outcome, highlighting the dangers of using historical controls when assessing new types of treatment or timing of surgery.

ROUND TABLE DISCUSSIONS AND PLENARY LECTURES

In the combined session with the Neuroanaesthetists Travelling Club, the Round Table Discussions focused on the interdisciplinary team approach required for successful interventional neuroradiology. (J EdmondsSeal, ER Hitchcock, A Molyneux, S Firn) and cranio-facial surgery (D Gordon, TAH Hide, M Wake, V Goat). In the Sir Hugh Cairns Memorial Lecture, PH Schurr remembered the life and times of the founder of neurosurgery in Oxford on this 50th Anniversary of its establishment.

THE MANAGEMENT OF PITUITARY TUMOURS AND POSTOPERATIVE VISUAL DETERIORATION CBT Adams: Oxford-Cairns Memorial Lecture, Hugh Carins Society of South Australia. 